\title{
Wirksamkeit auf Genom-Ebene nachgewiesen
}

Jüngste Daten einer Studie zur Akzeptanz von Lichtschutzmitteln in Außenberufen des Universitätsklinikums Dresden untermauern, dass das Bewusstsein für Sonnenschutz, auch während der Arbeitszeit, geschärft werden muss.

Nach ihrem Sonnenschutzverhalten befragt, räumten $72 \%$ der Außenarbeiter $(n=40)$ ein, bis dato nie oder selten Sonnenschutz während der Arbeitsund Freizeit angewendet zu haben. Nach Ablauf der Studie, bei der die Teilnehmer über zwei Monate Sonnenschutzprodukte, darunter ANTHELIOS XL 50+ Milch von La Roche-Posay, applizierten, zeigte sich jedoch: „80\% der Außenarbeiter würden dieses Produkt im Sommer täglich bei der Arbeit verwenden“,

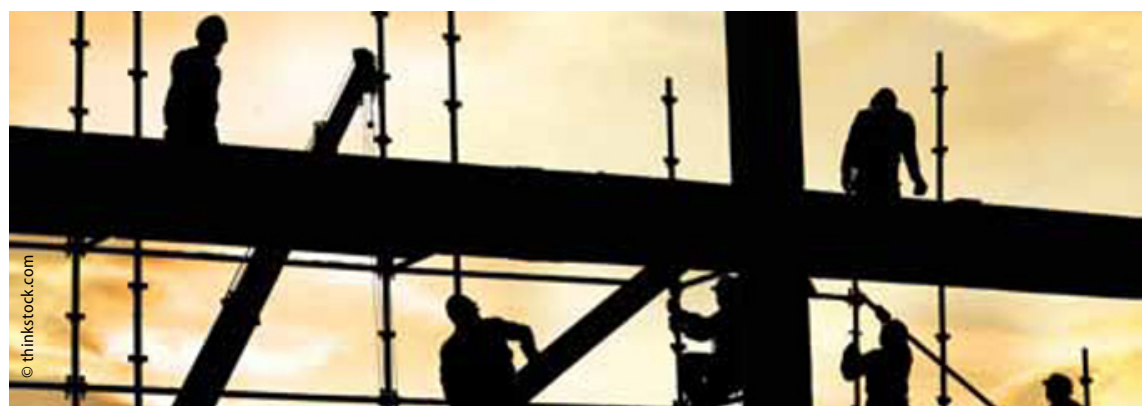

$(\leq 2,5)$ erreicht Mexoplex eine wesentlich höhere UVA-Protektion als herkömmliche Filtersysteme.

Neue Daten von Marionnet $C$ et al. belegen die Wirksamkeit von ANTHELIOS erstmals auf Genom-Ebene: Die durch UVA-Strahlung induzierte Modulation der Expression von Genen, die bei der Entstehung einer Photokarzinogenese, Photodermatose und Hautalterung von Bedeutung sind, wird nachweislich verringert [1].

Dank der synergistischen Effekte erzielt z.B. die Kombination der UV-Filter Mexoryl $^{\oplus} \mathrm{SX}$ und Tinosorb ${ }^{\circledR} \mathrm{S}$ bei niedrigerer Dosierung einen höheren UVB-Schutz als die Addition der Einzelfilter. Mexoplex enthält den Lösungsvermittler ELDEW ${ }^{\circledR}$ SL 205. Dieser erleichtert das Auftragen und trägt dazu bei, die Schutzwirkung bei geringer Filtermenge deutlich zu steigern.

\section{[1] Marionnet C, Krutmann J et al, Experimental Dermatology 2011, 20: 477-482}

Nach Informationen von La Roche-Posay zum Symposium Photodermatologie II, 27. Januar 2012, Berlin

\section{Neue Wirkstoffkomplexe reaktivieren die Genese der Hautzellen}

Die natürliche Hautalterung ist ein vorprogrammierter, normaler Prozess und wird begleitet von Strukturveränderungen in Oberhaut und Lederhaut sowie in deren Grenzbereich.

Hautalterung geht einher mit Elastizitätsverlust und Faltenbildung sowie dem Auftreten von PigmentunregelmäBigkeiten. Mit zunehmendem Alter verlangsamt sich die Erneuerung der Hautzellen. Abgestorbene Zellen verdicken die Hornschicht: der Teint wird stumpf, blass und ohne Ausstrahlung. Es kommt zu Hauterschlaffung und Veränderungen von Gesichts- und Körperkonturen.

Auf der Basis der jüngsten Erkenntnisse aus der dermatologischen und molekularbiologischen Forschung ist mit Noveane 3D ein revolutionäres AntiAging-Konzept entstanden.

\section{Zellerneuerung wird angekurbelt}

Durch die Kombination der Wirkstoffkomplexe Regenol DNA und Fibrolastyl 3D ist Noveane 3D in der Lage, die Struktur der Haut zu regenerieren. Regenol DNA mit Oligopeptiden und multi- lamellaren Ceramiden hat eine hohe Wirksamkeit gegen freie Radikale und ermöglicht die Reprogrammierung der Zellerneuerung. Fibrolastyl 3D stimuliert als innovativer natürlicher Bioaktivstoff die Bildung des Enzyms, das die Restrukturierung von Kollagen- und Elastinfasern aktiviert. Alle NoveanePräparate werden ergänzt durch weitere spezifische Wirkstoffe für einen strahlenden Teint und mehr Spannkraft.

Nach Presseinformationen von Dermatica Exclusiv Horst Spickermann GmbH 